\title{
THE DIACHRONIC MAPPING OF TEMPORAL FEATURES BETWEEN ENGLISH NOMINALS AND VERBS, AND THE ARTICLE-ASPECT INTERPLAY
}

\begin{abstract}
Aspect (the perfective-imperfective distinction) can be verbal or compositional. The probable distribution and re-distribution in diachrony of some aspectual devices in English are outlined in a bid to improve the description of aspect in Old/Middle English. The author's model of compositional aspect is employed with its conceptions of the temporal nature of situation participants, the mapping of temporal features between nominals and verbs in the sentence and the inverse relationship across languages of markers of temporal boundedness in verbs and nouns. Leiss' theory of the article-aspect interplay in Proto-Germanic in diachrony is also employed to complete a picture in which aspect in Old English after the emergence of the definite article must have been explicated in compositional terms like in Modern English.
\end{abstract}

Key words: English compositional and verbal aspect diachronically and synchronically; definite, indefinite and zero article; articles as markers of boundedness/non-boundedness; mapping of temporal values of NPs; articleaspect interplay

E-mail address: kkabakciev@gmail.com 


\section{Introduction}

Published in BELLS (2013) is an article in which the author points to my work as a "cornerstone of what is known today as compositional aspect" (Bulatović 2013: 65) - invoking a reaction with a discussion of what compositional aspect (CA) is. Obviously, such a discussion must begin with what aspect is. In my understanding, it is a universal phenomenon found in all languages in different disguises but it manifests itself in two structural versions, verbal aspect (VA) and CA, that are mirror images of each other (Kabakčiev 2000: 158-161). VA is prototypically represented by the perfective-imperfective contrast in verbs as lexical entries in many extinct and modern languages: Proto-Indo-European, Early Old English, Gothic, Latin, Old Church Slavic, today's Slavic languages, Greek, etc. The perfective-imperfective contrast is also found in Modern English (ModEng) and closely related languages - systematically, but it is not expressed (marked/denoted/encoded) by verbs as lexical entries. It is mainly explicated/signaled at the sentence/clause level in terms of two semantico-syntactic schemata, a perfective and an imperfective one, discovered by Verkuyl (1972) and known as CA. When found in verbs as lexical entries (as in the Slavic languages) or in the syntactic realization of verbs (as in the English progressive), it is an instantiation of VA. Thus CA and VA are two different types of aspect in terms of language structure but not in terms of semantics.

Although CA is already five decades old and described in hundreds of publications (correctly or not quite), many linguists still have no idea what CA is (also because it is absent in grammars, see below). Let me, therefore, briefly demonstrate how CA works. In (1a-b), perfectivity is signaled: a completed event, temporally bounded. It arises through the so-called quantified/bounded situation participants - bounded through articles, determiners, quantifiers, pronouns, proper names, etc., and mapping their boundedness onto the verb referent. If a participant becomes non-bounded losing its bounding element, the so-called (by Verkuyl) aspectual leak occurs; the sentence becomes imperfective, cf. (1c-d). The leak can be in the verb, too: (1e) is perfective because the verb is telic; (1f) is imperfective because the verb is atelic (Verkuyl 1972; 1993; Kabakčiev 2000; 2019; Bulatović 2019; 2020). 
Krasimir Kabakčiev: The Diachronic Mapping of Temporal Features between English...

(1) a. Den Uyl gave the Labour party badge to a congress-goer

b. Two patients here died of jaundice

c. Den Uyl gave the Labour party badge to congress-goers

d. Patients here died of jaundice

e. X played the sonata

f. $\mathrm{X}$ hated the sonata

$\mathrm{CA}$ is extremely intricate and its explanation requires complex argumentation. A major element in my model of CA (Kabakčiev 1984; $2000 ; 2019)$ is that participants in situations are temporal entities in the minds of speaker and hearer. ${ }^{1}$ In (1a-b), temporal boundedness, marked on the situation participants by articles, quantifiers, proper names, etc., is mapped onto the verb referent, triggering perfectivity in it, with some help from the verb itself, its telicity. In (1c-d), the zero article and the plurality marker trigger non-bounded iterativity in the participants and this non-bounded iterativity is mapped onto the verb referent, triggering imperfectivity in it. Thus CA is explained through the impact of articles (definite and indefinite as exponents of boundedness, zero article as an exponent of non-boundedness), unlike in some publications where the existence of aspectual functions of articles is rejected - with little argumentation or none at all (Młynarczyk 2004; Czardybon and Fleischhauer 2014; Fleischhauer and Czardybon 2016; cf. my response Kabakčiev 2018), or the authors simply fail to see it (Berezowski 2011; Sommerer 2018; Gelderen 2018). In the other camp, that of linguists who duly recognize the decisive impact of articles for aspect (Verkuyl 1972; Leiss 2000; Abraham and Leiss 2012), Bulatović has just published two papers, in the first of which she convincingly argues that CA, with the crucial role of articles, is such an important phenomenon that it must be taught to all learners of English around the world, not only to Slavs (Bulatović 2019). In the second, she strongly criticizes English grammars for their inadequate treatment of aspect as a result of either a profound misconceptualization of CA or lack of knowledge of it and calls for a radical change in their treatment of aspect, tense, nominal determination and aspect-related adverbials (Bulatović 2020).

My aim here is to demonstrate how aspect was - probably - explicated in compositional terms in the history of English, and to outline the distribution or re-distribution of some aspectual devices. This ought to

1 Participants in situations (a term introduced in Kabakčiev 1984) are also called verb arguments. 
help the understanding of the English aspectual system in diachrony, with its radical restructuring from a prototypical VA system in OldEng to a fullblown CA system in ModEng. My model follows to a certain extent Verkuyl's (1972; 1993), and is based on: (i) the inverse dependence across languages of markers of temporal boundedness in verbs and nouns; ${ }^{2}$ (ii) its underlying conception of the temporal nature of participants in situations and the mapping of temporal features between referents of nominals and verbs in the sentence/clause (Kabakčiev 1984; 2000; 2019); ${ }^{3}$ and (iii) Leiss' (2000) theory of the aspect-article interplay in Proto-Germanic. The diachronic description mentioned above is necessary because, as already shown, the Old English (OldEng) aspectual system appears a puzzle because of the severe misunderstanding of aspect not only in Middle English (MidEng) and OldEng but also in ModEng. Aspect in OldEng/MidEng ought to be based on ModEng - but this is impossible with the failure of ModEng grammars to describe its aspect system (Bulatović 2013; 2020). They do not offer a word on the article-aspect interplay; they severely lag behind linguistic research, and their inadequacies went unnoticed for decades, with rare exceptions (Schüller 2005; Bulatović 2013). After 2000, a ray of hope shone, some ModEng grammars started to admit - slowly and shyly - that perfectivity in English exists (Huddleston and Pullum 2002: 118-125; Downing and Locke 2006: 370; Declerck et al. 2006; Langacker 2008: 147ff; Fenn 2010: 277-281), but with no hint of explanation where it suddenly sprang from. ${ }^{4}$ In any case, the article-aspect interplay remains a terra incognita in English grammars, ${ }^{5}$ a fact uncompromisingly revealed by Bulatović (2020).

2 This dependence was formulated in Kabakčiev (1984) and developed in Kabakčiev (2000). Abraham and Leiss (2012: 326) point to these publications as "the first to note that languages develop either a category of aspect or an article system".

3 "Participants in situations" is a term introduced in Kabakčiev (1984) to refer to verb arguments that take part in the aspectual composition. In Verkuyl's (1972: 98ff) terminology these shape "the upper bound of the aspects".

4 Declerck et al. (2006) stands apart from other grammars with the inclusion in it of certain elements of Verkuyl's theory, without Verkuyl being credited (Declerck et al. 2006: 79). The author explains that "grammars are typically written without systematic references to the linguistic literature" (Declerck et al. 2006: 4).

5 But see Kabakčiev (2017), an English grammar which describes the interplay in detail, see Bulatović (2020). 


\section{Articles - what are they for?}

Most languages have no articles (Heine and Kuteva 2006: 101-103) and standard descriptions of articles contain an explanation that the indefinite article is attached to a noun appearing for the first time in the discourse, whereby the nominal referent is identifiable for the speaker and not for the hearer. The definite article is attached to a noun already introduced or to one whose referent is somehow identifiable to speaker and hearer (Heine and Kuteva 2006; cf. Hewson 1972: 85-116, Hawkins 1978: 172221; Lyons 1999: 1-13; Huddleston and Pullum 2002: 368-372). Thus, if other markers of definiteness/indefiniteness - pronouns, demonstratives, quantifiers, proper nouns etc., are ignored, in a language with a regular pattern of a definite and an indefinite article such as English, the first appearance of a noun will in most cases be with an indefinite article, ${ }^{6}$ and all its following appearances will be with a definite article - or the nominal will be marked definite otherwise. But if in its first appearance a noun is indefinite and in each following appearances it is definite, an important question arises, one that is almost never asked: is the article, viewed as an integral unity of the definite and the indefinite article (i.e., not as a marker of definiteness and indefiniteness separately), necessary at all?

When languages have only one article, it is often definite rather than indefinite (Heine and Kuteva 2006). But logic actually points to the need for the opposite. If definiteness/indefiniteness must be outwardly expressed (for some reason yet unknown), and if we take it that language is better represented in texts rather than isolated sentences, what happens when a noun must be used 50 times in a text/discourse? It will be indefinite the first time, and then definite 49 times. Obviously, the principle of economy ought to interfere and "rule" that it is appropriate to have an indefinite article for indefiniteness and no article for definiteness. On the other hand, even the indefinite article appears superfluous: because the hearer will normally sense if a noun is emerging for the first time in a discourse. If it is, its referent is indefinite. And when this noun pops up a second, third, or $\mathrm{n}^{\text {th }}$ time, it will be recognized as known and treated as definite. This is obviously what happens in languages without articles. Why, then, this burden of marking nouns as indefinite, when it is clear they are indefinite?

6 Barring exceptions where the entity is shared knowledge between speaker and hearer (the sun, etc.) and taking into account that this is valid for singular count nouns - plural and mass nouns are not afforded an indefinite article. 
Why marking nouns definite when they are obviously definite? Why should the definite article be the most frequent word in English (according to the Oxford English Corpus) if marking definiteness is even less necessary than marking indefiniteness? What is the raison d'être of the articles? The answer to this question was provided a long time ago: the article, i.e., the regular pattern of a definite and an indefinite article, marks temporal boundedness on participants in situations, and this boundedness is then mapped onto the referent of the verb (Kabakčiev 1984; 2000; 2019). ${ }^{7}$ This is the raison d'être of the article - as a unified entity of $a$ and the.

\section{The English definite article diachronically as an exponent of temporal boundedness}

Example (2) below is a MidEng sentence from Cursor Mundi (1300 A.D.). It contains three situation participants, like (1a) above: she 'she', pe childe 'the child' and pe welle 'the well':

(2) She dud pe childe drynke of pe welle 'She made the child drink from the well'

Let us analyze the aspectual value of dud 'made' (not of drynke). It is perfective as a default, prototypically. ${ }^{8}$ Being MidEng, not OldEng - where there would be no articles but either verbal prefixes or other specific perfectivization devices, (2) features articles and lacks verbal aspect, in the sense that $d u d$ is not perfective like many verbs in previous stages of the language, mainly prefixed (on perfective prefixed verbs see Senn 1949; Mustanoja 1960: 446; Gelderen 2007: 294; 2018: 21). According to Verkuyl's and my own CA model, perfectivity here arises through the definite articles in pe childe and pe welle, marking temporal boundedness on the referents of the nominals, and through the pronoun containing a covert definite article (she = "the woman previously mentioned"). The temporal boundedness of the participants is then simultaneously mapped onto the referent of the verb dud (see Kabakčiev 2000; 2019). The verb is telic, which precludes the possibility for an imperfective leak.

7 This is part of a complex mechanism that cannot, for space restrictions, be presented here in depth.

8 On default, prototypical CA readings, see Kabakčiev (2000: 59, 137; 2019). 
Note that of pe welle is a situation participant. It may look like an adverbial rather than an indirect object, but whether it is one or the other is a moot question. In any case, contrary to Verkuyl's (1972: 98ff) reasoning about what he calls the upper bound of the aspects, ${ }^{9}$ it takes part in the explication of aspect. Cf. ModEng (3a), which is a prototypically perfective sequence, no matter whether the article is $a$ or the, whereas (3b) is prototypically imperfective, with a non-bounded iterative reading due to the imperfective leak in from wells (3b):

(3) a. She made a/the child drink from a/the well

b. She made a/the child drink from wells

Now, if sentence (2) is to be "shifted back in time" to a language stage prior to the emergence of articles, it would have to have a hypothetical form such as (4). The absence of articles makes its translation into ModEng difficult:

(4) *She dud childe drynke of welle ${ }^{10}$

'She made child drink from well'

Note that while ModEng (3a) explicates a single perfective event, the hypothetical (4) without articles in two nominals does not. The aspectual value of $d u d$ here can be described as "not necessarily perfective". It could be perfective (single event) or imperfective (non-bounded iterativity) because of the elusive referential status of childe and welle (see below).

In (3a) the covert definite article in the subject allows the substitution of she with the woman with no change of aspectual meaning - (5a). This allows the construction of sentence (5b) in ModEng, formed by stripping the grammatical (5a) of all the articles - in a hypothetical world in which the English language does not feature articles:

(5) a. The woman made the child drink from the well

b. *Woman made child drink from well

9 See below on whether instrumental adverbials, a similar type of adverbials, take part in the explication of aspect (discussed in Verkuyl 1972).

10 An anonymous reviewer points out that the hypothetical sentence (4) here is MidEng rather than OldEng and that in OldEng it would probably read Heo dyde cild of welle drincan. In any case, the hypothetical MidEng (4) and the hypothetical ModEng She made child drink from well illustrate a language without articles (or other markers of boundedness on nouns) and without perfective verbs at the same time - and such a language is conjectured here not to exist (see below). 
Apart from hypothetical, (5b) is, of course, also non-grammatical. As for (4), we cannot label it non-grammatical, as there are no MidEng/ OldEng speakers to offer judgement. Hence, let us call it hypothetical only, and test (4) and (5b) against existing languages without articles. In such a test on Slavic data, translation is facilitated, there are no articles to insert. Something else is obligatorily required for insertion, however: perfective or imperfective aspect in the verb. Compare (4), (5b) and Serbian/Russian (6a-b):

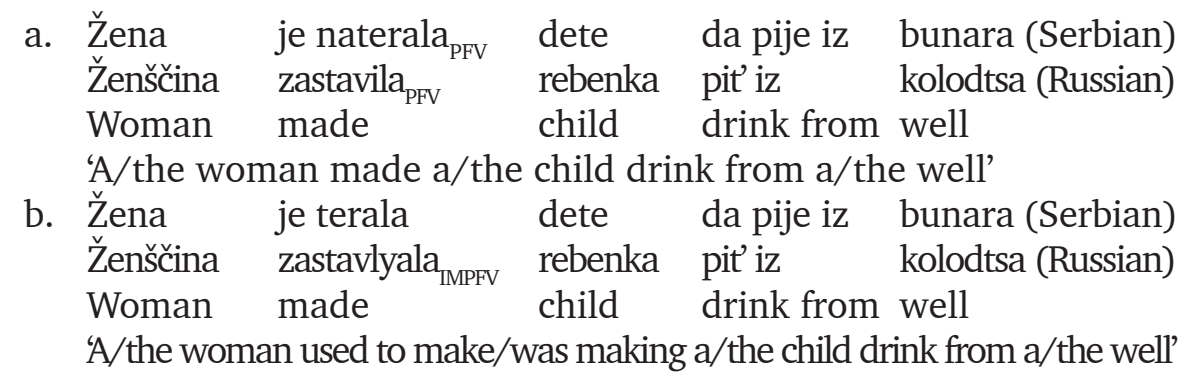

What strikes the eye in this comparison is that while the Serbian/ Russian sentences without articles are semantically and grammatically immaculate, the English one without articles is fully incomprehensible as to what the woman did. Did she make the child drink once? Several times? Often? Always? Such incomprehensibility in Slavic is non-existent, impossible, thanks to the aspectual options in the verb. If we take it that sentence (4) could exist at such a stage of development of OldEng in which perfective verbs have already disappeared but a definite article is still not yet available, and that a sentence such as (5b) can exist in hypothetical ModEng with no articles, a serious question arises: is such a language possible? It appears logical to assume that a language without articles and verbal aspect simultaneously, as in (4) and (5b), cannot exist! And this is not necessarily because of the simultaneous absence of articles and verbal aspect - something abstract, theoretical, but for an earthly reason. Sentences like (4) and (5b) without articles/determiners in the nominals fail to tell the hearer whether this is a single occurrence of an action or a non-bounded/bounded repetition thereof, something hardly admissible in communication. This allows the hypothesis that the demise of perfectivity in the verb and the birth of the definite article in OldEng happened simultaneously, not one after the other. Note the intriguing circumstance that whether perfectivity or imperfectivity is signaled in (5a-b) depends 
not on the verb but on the presence/absence of determiners in the nominal components, and it may even depend on a single nominal (see below).

Thus, when transferring (5b) into a Slavic language without articles, two variants occur: a perfective verb for made denotes a single act; an imperfective one portrays the act multiplied an indefinite number of times, cf. (6a-b). ${ }^{11}$ When the hypothetical construct (4) is transferred into ModEng, a language with obligatory articles, the ensuing situation is similar, in the sense that, with the relevant articles supplied, the sentence is prototypically perfective (a single completed action) in consistence with CA rules, cf. (3a), (5a). This event can be multiplied a definite number of times by a bounded-repetition adverb, producing another well-formed perfective sentence:

(7) The woman made the child drink from the well three times

But if a Verkuylian leak appears in any nominal component, the aspectual reading of made becomes imperfective by default (prototypically):

(8) a. The woman made children ${ }_{\text {LEAK }}$ drink from the well

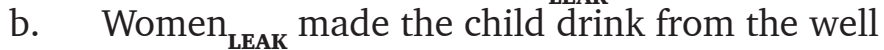

c. The woman made the child drink from wells LEAK $_{\text {LE }}$

This is because a single bare NP with a plural marker (children, women, wells), i.e., containing a Verkuylian leak, is sufficient to trigger non-bounded iterativity in the nominal referent and then in the verb associated with it (made). The non-bounded iterativity of the nominal's referent - the nominal being not spatial but temporal although it denotes a "physical entity" - is mapped onto the verb's referent, generating imperfectivity in it (Kabakčiev 2000; 2019). Note that while the leak imperfectivizes the relevant verb generating a non-bounded iterative meaning in it, it does not trigger a progressive-like imperfective meaning in made in the three sentences in (8). This circumstance, along with the fact that in many languages there are no articles, yet no need is felt in them to mark definiteness and indefiniteness, leads to the assumption that the two ModEng articles ( $a$, the) exercise a common function. This function, identified long ago (Kabakčiev 1984; 2000), is to mark temporal boundedness on situation participants - and

11 A progressive-like meaning is also possible in (5b). Note also that, contrary to some authors' assumptions, Slavic perfectivity does not necessarily force definite readings on direct objects or NPs in prepositional phrases (hence rebenka/dete is either "the child" or "a child"), although there may be certain tendencies. 
it concurs with the function of the zero article to mark temporal nonboundedness on participants. The idea of the common function of the articles ( $a \&$ the) to encode temporal boundedness may have less supporters (Leiss 2000; Abraham and Leiss 2012; Bulatović 2013; 2019; 2020) than adversaries (Młynarczyk 2004; Czardybon and Fleischhauer 2014; Fleischhauer and Czardybon 2016; Gelderen 2018), but it offers definitive solutions to issues related to the article-aspect interplay (Kabakčiev 2019).

Now it can be discussed in further depth how the articles in (3a), (5a) contribute to the explication of the event as a singular one. Obviously, the article (a/the) supports the non-iterative (single-occurrence) status of the relevant nominal: (5a) and all the sentences derivable from (3a), using the different combinations of $a /$ the, have a common parameter, namely, non-iterativity. Conversely, the three sentences in (8), each of which has a bare plural (marker of plurality), explicate the opposite, iterativity. The iterativity is non-bounded, arising out of the "non-bounded recurrence" feature of only one of the three nominals (situation participants). A question that now begs asking concerns the significance in language of the contrast between a single completed (perfective) event and a nonbounded iterative one (imperfective). It can be conjectured that single completed events are more important than iterative non-bounded ones in human communication - and the former certainly prevail in frequency over the latter. Hence an important general rule appears to exist, traversing all languages: the explication or direct denotation of single perfective events must be guaranteed by language structure!

Let us return to (5b). Can it guarantee the explication or direct denotation of a single perfective event? The answer appears negative. Despite the singularity of the three nominals, which ought to presuppose a single event, this is exactly what this sentence cannot guarantee. The construct (5b), if it had a legitimate existence, would mean "A/the woman used to make a/the child drink from a/the well", i.e., it would trigger a non-bounded iterative situation, just like Serbian/Russian (6b) does. Thus, the analysis of the hypothetical (5b) in a language containing these lexical items leads to the assumption that they must be governed by a grammar capable of blocking the non-bounded iterative reading.

Is this requirement met (in one way or another) in the languages discussed here - Serbian, Russian, English? For Serbian and Russian, the answer is positive. The non-bounded iterative reading is blocked by the perfective aspect in the verb: sentences such as (9a) are non-grammatical. 
Obviously, the denotation of single perfective events is guarded by the language structure. Note that while the perfective aspect in the Slavic verb does not allow a non-bounded iterative (imperfective) reading in such sentences, it allows a bounded iterative one - which is again perfective and arises when the sentence is complemented by adverbials like tri puta/ tri raza 'three times', cf. (9b):
a. *Žena je često *Ženščina často
naterala zastavila dete da pije iz bunara (Serbian) Woman often rebenka pit' iz kolodtsa (Russian) 'The woman often made a/the child drink from a/the well'
b. Žena je tri puta naterala dete da pije iz bunara (Serbian) Ženščina tri raza zastavila rebenka pit' iz kolodtsa (Russian) Woman three times made ${ }_{\mathrm{PFv}}$ child drink from a/the well 'The woman made a/the child drink from a/the well three times'

However, in English the system works differently: (5a) in its default, prototypical reading explicates a single event; indeed, it does not exclude the possibility for non-bounded iterativity, but an additional element in the sentence/context is normally required for this to obtain - an indefiniterepetition adverbial (often, regularly) or a periphrastic imperfective marker of indefinite repetition (used to, would):

(10) a. The woman often/regularly made a/the child drink from a/ the well

b. The woman used to/would make a/the child drink from a/ the well

Note here that, due to the failure of English grammars to identify the devices for aspect explication, English would and used to have always been described not as aspectual markers, of imperfectivity, but as "markers of habituality". The reason for the misnomer is clear. If would and used to had been termed markers of imperfectivity, this would require an explanation of where the exponents of perfectivity are, an explanation impossible without the discovery of CA. ${ }^{12}$ But in any case, in English too, language structure takes care of the explication of single perfective events, effectuating it in this intricate manner within Verkuyl's perfective semantico-syntactic schema, illustrated by sentence (5a), demonstrating the momentous role

12 And even later, as the CA theory became slowly better understood. On vicissitudes in CA history, see Kabakčiev (2019). 
played by the article - in this case in three sentence components. The article, assisted by the telicity of the lexical verb, generates a status of single occurrence and temporal boundedness in each of the relevant NP referents - the woman, the child, the well, to bring about the final perfective reading of the verb (made).

\section{Aspect - what exactly is it?}

Aspect, represented by the perfective-imperfective distinction, is a fundamental notion critical for the description of language structure. It is a phenomenon occurring in all languages but in different disguises, yet omnipresent in every language - in the sense that every sentence/clause containing a verb in a meaningful text expresses or signals perfectivity or imperfectivity. Perfectivity is a situation (in terms of Vendler's 1957 model of situations), which is temporally bounded and has an initial- and an endpoint. These two points, together or separately, can be subsumed in a sentence/clause or outwardly given. A perfective situation, apart from being bounded, is also normally "brought to a natural end", whereby the "natural end" is interpreted in broad pragmatic terms, as an inherent result of the situation at the endpoint. ${ }^{13}$ Conversely, imperfectivity is a temporally non-bounded situation, whether or not an initial- and/or an endpoint are present or subsumed, whether it describes a generally valid state of affairs or an indefinitely repeated one, or a current activity (as with the progressive). It is worth noting here that the perfective-imperfective contrast may sometimes - rarely - be impossible to explicate because of specificities in the semantics of certain ModEng verbs (11a), ${ }^{14}$ or it may be irrelevant to both speaker and hearer, as in OldEng (11b), Sommerer's (2018: 80) example:

(11) a. John pushed the cart

b. æfter pan pæt lond wearð nemned natan leaga 'After that, the land was called Netely'

13 This is valid for prototypically perfective situations. There are non-prototypical perfective situations too (quasi-perfective), termed "episodes" (Kabakčiev 2000: 279-307), with a somewhat lower prevalence.

14 The verb push is neither telic, nor atelic - there are just a handful of such verbs in English. 
Krasimir Kabakčiev: The Diachronic Mapping of Temporal Features between English...

Such cases of "absence of aspect" in a sentence in English are exotic. They are very rare, hence negligible.

\section{What aspect is not; what it must be}

Aspect is not what English grammars have been teaching readers for decades: a distinction between simple and perfect and/or simple and progressive forms (Quirk et al. 1985: 189ff; Hogg 2002: 40; Carter and McCarthy 2006: 405ff; Downing and Locke 2006: 372; Eastwood 2006: 14ff). The progressive is, of course, an aspect: an exponent of imperfectivity restricted to ongoing actions and currently valid states. But it must not be contrasted with the indefinite tenses, including the preterite, because these have no aspectual meaning. ${ }^{15}$ What aspect is must be structurally visible, in the form of tangible components. For example, Slavic aspect is visible. It is a grammatical distinction whose exponents reside in the verbal lexicon: every verb has an easily identifiable aspect (perfective/imperfective), save for a small group of verbs called biaspectual. English imperfective aspect, represented by the progressive and the used to/would markers of imperfectivity/habituality, is a tangible structural entity too, as is aspect in Proto-Indo-European, Gothic or OldEng in the form of perfective (usually prefixed) versus imperfective verbs (Streitberg 1891; Mustanoja 1960; Wood 2002; Młynarczyk 2004).

What is not visible, or is at least very difficult to see, is aspect in languages like MidEng or ModEng - explicated compositionally in an extremely intricate way at the sentence/clause level. But VA, otherwise visible, is also not easy to understand. Drobnak (1994: 123) notes about OldEng ge- that despite the numerous publications purporting to explain its meaning and function, they remain inconclusive, so she abstains from the analysis of aspect (Drobnak 1994: 123). But despite other contentions that the OldEng verbal prefix ge- is not a perfectivizing one (Lindemann 1970: 1), most scholars maintain the opposite view (Senn 1949; Mustanoja 1960: 446; Gelderen 2007; 2018). As for ModEng, perfectivity there is mainly explicated compositionally, through a complex interplay of lexical, semantic and grammatical elements at the sentence/clause level - but it can

15 The English preterite is like "an empty bag". It has no aspectual meaning of its own and can accommodate any aspectual value generated in the sentence/context (Kabakčiev 2017). 
also arise in the larger context (Kabakčiev 2000: 59), and be, furthermore, influenced (eliminated/generated) by pragmatic factors, "knowledge of the world" (Kabakčiev 2000: 309-326). Therefore, along the lines of the present approach, aspect, a universal phenomenon in different disguises, ought to have its own structural (visible, tangible) components (that may be very different) in all languages. Hence, in the long run CA can also be said to be visible through Verkuyl's schemata. But it is not readily available to the "naked eye" of the average speaker, as it requires specific knowledge.

\section{Fall of aspect, rise of articles in Proto-Germanic - Leiss' theory}

OldEng had no articles. They started to emerge in late OldEng, the definite first, later the indefinite. VA started to lose ground earlier; in early MidEng it was already gone (Mustanoja 1960; Gelderen 2007; 2018; Macleod 2012). As pointed out by an anonymous reviewer, some historical linguists (e.g., Ringe and Taylor 2014: 447-449, 464 - along with others), argue that in earlier stages of OldEng there were items functioning as articles: demonstratives, quantifiers (an 'one', sum 'some'). This thesis confirms the conjecture that the demise of perfectivity and the birth of the article must have occurred gradually and simultaneously, not one after the other, and that the disappearance of verbal perfectivity had to be made up for. On the other hand, the argument about items in OldEng functioning as articles is loose - because demonstratives, quantifiers and similar elements are in wide use also in languages that have no articles, and never had (Latin, Russian, Serbian, etc.). Due to the (previous) absence of a definition of the raison d'être of the articles ( $a$ and the), in historical linguistics there has never been a criterion to distinguish "a true article" from an article-like entity. The main reason is that $a$ and the have always been investigated not as an integrated entity, "an article", but separately, as exponents of "definiteness" (the) and "indefiniteness" (a) respectively. This approach completely fails to explain (among other things) why indefiniteness is marked with an article with count nouns and not marked with non-count nouns. As already argued here and elsewhere (Kabakčiev 1984; 2000; 2019), the major function of the article (i.e., the integrated " $a+$ the entity"), its raison d'être, in English and similar languages is to mark temporal boundedness on situation-participant NPs and thence perfectivity in certain 
semantico-syntactic schemata - while definiteness and indefiniteness are residual functions.

The world linguistic community owes the discovery of a link between the demise of aspect and the birth of a definite article to Leiss (2000), who investigated three Proto-Germanic languages, Old Icelandic, Gothic and Old High German, and found that that they featured a definite article, no indefinite article, and a correlation between the weakening of aspect and the strengthening of the definite article. Perfectivity in Leiss' model is a form of "verbal definiteness", analogous to nominal definiteness. Her observations on how perfective verbs were gradually substituted by definite articles are extremely valuable because they describe what happened in the history of not just one but of three languages. Furthermore, what happened was not accidental, it involved remarkable systematicity. The substitution of perfectivity with a definite article was accompanied by a whole plethora of phenomena and/or changes in different spheres: use of the accusative vs. genitive/partitive case distinction for explicating perfectivity and imperfectivity; use of verbs in the historical present together with the definite article (Old Icelandic) to express perfectivity (Leiss 2000: 73-75); the definite article in Old Norse ensured the perfective reading of the historical present - which was not a stylistic device there but a perfectivization tool (Leiss 2000: 99); the initial sentence position of a verb in Old Norse also served as a perfectivization tool (Leiss 2000: 84-88); when prefixes of perfective verbs with a past meaning started disappearing in Old Norse, there came the definite article taking up the function of the prefixes (Leiss 2000: 80-82); the definite article in Gothic and Old Icelandic was found to be primarily an aspectualizer, as it did not originally function to indicate that a NP is to be taken as definite - definite NPs in these two languages represented by proper names, subjects and objects in definite syntactic environments were not additionally marked by the article (Leiss 2000: 159).

Unfortunately, the core of Leiss' (2000) insightful work remains misunderstood and ignored (barring certain exceptions - Abraham 1997; 2017; Fischer 2005; Wood 2007; Bauer 2007; Kabakčiev 2018). Two recent publications stand out as representative of the drift. In a large study of article emergence in OldEng, Sommerer (2018), instead of using the opportunity to explore whether article emergence is not a result of the loss of aspect and then endorse or reject Leiss' model, has just a couple of words to say in a footnote on the article-aspect link (Sommerer 2018: 
47). Another new book in the same sphere, dealing with aspect, verbs and verb arguments diachronically (Gelderen 2018), also sidesteps Leiss' article-aspect interplay, barely mentioning it. A decade earlier, Gelderen (2007: 275) had noted Leiss' assertion that definiteness and specificity can be expressed through VA, but the possibility for an article-aspect link is abandoned in Gelderen (2018). An idea from the early and naïve stages of linguistics is maintained instead, viz., that when ge-perfective prefixes are lost in Early MidEng, "this role [perfectivizing] is taken up by optional telic particles, such as up" (Gelderen 2018: 21). It thus turns out that perfectivity arises mainly or even solely through particles. But these allegedly perfectivizing particles, as is common knowledge, are very far from numerous and are not widely used in English at all. What is more, the naïve view about "telic particles" evades the circumstance that there exist millions of perfective sentences in English without particles - such as (1a,b,e), (3a), (5a), (7). If perfective aspect were expressible mainly through particles, the perfectivity of such sentences would remain a true mystery. Of course, their perfectivity, apart from demonstrated here, was explained in depth half a century ago by Verkuyl (1972).

Along with Leiss, Gelderen argues that the genitive-partitive vs. accusative alternation indicates "a connection between measure and affectedness of the object, i.e., definiteness, and aspect" (Gelderen 2018: 101). But Gelderen sidesteps this issue too, proposing no aspect-case link in which the article, a nominal component, has an impact on aspect - together with or alongside case. She writes: "Where Old English has specialized case and some use of demonstratives to mark definiteness and verbal prefixes and inflections to mark aspect, Modern English uses articles for definiteness and particles and auxiliaries for aspect" (Gelderen 2018: 2). In other words, for Gelderen (2018) particles are used for aspect, while the article has nothing to do with aspect - it only marks definiteness. Apart from that, actually it is precisely the opposite thesis, that perfectivity can be ultimately explicated through the article, that is in need of special consideration, rather than the much more obvious one - that the perfectivity of a verb may lead to interpretations such as definiteness, specificity, etc. of an object NP. A researcher who wishes to subscribe to Leiss' theory of the article-aspect interplay will always need to explain how an article, a NP component, serves the signaling of perfectivity, something related to the verb (see the issue handled above and in Kabakčiev 2000; 2019). 
To sum up, the article-aspect interplay, a phenomenon of supreme importance for English grammar synchronically and diachronically, remains severely neglected in the literature, including grammars (see Bulatović 2013; 2020). If Sommerer (2018) and Gelderen (2018) in particular, had not turned a blind eye to Verkuyl's (1972) CA theory, the theory of the Germanic article-aspect interplay in diachrony (Leiss 2000), and the inverse dependence of markers of temporal boundedness with its underlying mechanism of mapping temporal features (Kabakčiev 1984; 2000), a completely different description of MidEng/OldEng grammar could have emerged in the concrete domain - handling together articles and aspect. Below it will be shown again that a correct explanation of English aspect in diachrony can hardly be successful without taking into account the theoretical models above.

\section{MidEng/OldEng data demonstrating the article-aspect interplay}

It is worth asking to what degree the CA theory can be suitable for analyzing a language like OldEng in view of the absence of articles in the relevant time periods. Examples from OldEng/MidEng with definite articles/ demonstratives allow applying Verkuyl's perfective and imperfective schemata. For example, it can be supposed that the subject in (12a) below (from Gelderen 2014: 106) could just as well be without an article or a demonstrative, cf. (12b). Consider the two sentences, with pa bodan 'the messengers' in the first and bodan 'messengers' in the second. The lack of an article/demonstrative in the second turns the perfective (12a) into imperfective (12b):

(12) a. Da bodan us færdon

'The messengers frightened us'

b. Bodan us færdon

'Messengers frightened us'

Although Gelderen (2018) discusses OldEng/MidEng aspect at length, she fails to notice the impact of the definite article for explicating aspect, due to disregarding or misconceptualizing CA. ${ }^{16}$ In the two cases above, (12b)

16 Was Gelderen not familiar with Verkuyl's theory? Verkuyl (1993), proposing a more sophisticated CA theory, is part of Gelderen's (2018) references, so this is obviously not the case. 
falls into Verkuyl's imperfective schema, while ba 'the' in (12a) bounds the referent of the subject, making it a temporally bounded entity in the mind of speaker/hearer - a single appearance of messengers. The temporal boundedness of pa bodan 'the messengers' is mapped onto the referent of the verb, triggering perfectivity. Conversely, the bare plural in (12b) "unbounds" the messengers. It produces a non-bounded time series of messengers instead of a single appearance. The temporal non-boundedness (indefinite iterativity) is then mapped onto the referent of the verb, coercing it into imperfectivity (Kabakčiev 2000; 2019). This conception of the temporal nature of participants and the mapping of temporal values (Kabakčiev 2000) appeared, indeed, later than Verkuyl's (1972) CA, yet almost two decades earlier than Gelderen (2018) to be easily discounted.

Perhaps the temporality of $p a$ bodan 'the messengers' and bodan 'messengers' is difficult to understand? Taking this into account, a "common-sense" explanation was proposed a long time ago (Kabakčiev 2000: 99ff), called a "TV representation". It consists in conceptualizing participants not as static images but as moving pictures, a video. If (12a-b) are explained through a "TV representation", pa bodan in (12a) is not a static picture of physical entities but a moving picture (a video) of people (messengers) appearing on the TV screen and/or in the speaker's/hearer's head in a single instance. Conversely, bodan in (12b), without a determiner, is, again, not a static picture of human beings but a moving picture on the screen and/or in the speaker's/hearer's head. But now they are a nonbounded temporal series of messengers, indefinitely re-occurring, not a single occurrence of messengers as in (12a). The explanation is valid, of course, not only for OldEng (12a-b) but also for their ModEng translations.

This is how perfectivity/imperfectivity in (12a-b) arises in OldEng/ MidEng, at a stage when an article is already present. In the same way as in ModEng, thanks to the article-zero article contrast in structural language terms, on the one hand; and, on the other, thanks to the ability of the human brain to process situation participants as moving pictures, though in a specific way. It is intriguing why this ability of the brain remains hidden for the native speaker and even the linguist. Obviously, the brain has the ability to subsume the separate occurrences of "physical objects" under concepts that are stable in time as a memory-saving technique (Kabakčiev 2000: 117); why the ability is "hidden" is an open question. 
As mentioned, Sommerer's study of article emergence in OldEng sidesteps the article-aspect interplay. Yet some of its data, like Gelderen's (2018), provide proof of the role the definite article plays in marking boundedness on participants, beyond the author's awareness. For example, (13), from Sommerer (2018: 80), manifests perfectivity - triggered by $p a$ 'the' and Jæm 'those/the':

(13) by ilcan geare drehton pa hergas on East Englum and on Norðhymbrum West Seaxna londs wiðe be pæm suðstæðe mid stælhergum, ealra swipust mid ðæm æscum pe hie fela geara ær timbredon

'The same year the raiding armies attacked East Anglia, Northumbria and Wessex widely along the south coast with predatory bands most of all with the/those ships which they had built many years earlier'

If these two determiners in (13) are deleted to obtain (14), indefinitely repeated attacks are now described instead of an attack viewed as a single act in (13). The article/determiner is gone, and with it its bounding function; drehton 'attacked' now signals imperfectivity (non-bounded iterativity). ${ }^{17}$

(14) py ilcan geare drehton hergas on East Englum and on Norðhymbrum West Seaxna londs wiðe be pæm suðstæðe mid stælhergum, ealra swipust mid æscum pe hie fela geara ær timbredon

'The same year raiding armies attacked East Anglia, Northumbria and Wessex widely along the south coast with predatory bands most of all with ships which they had built many years earlier'

Sentences (13-14) with their ModEng translations are interesting in terms of the CA theory with the role an instrumental adverbial can play for signaling aspect. Verkuyl (1972: 109) maintains that instrumental adverbials are beyond what he calls the upper bound of the aspects. Later research (Kabakčiev 2000: 260-262) showed that instrumental adverbials can trigger perfectivity or imperfectivity. This happens in (13-14) through the article-zero article contrast in mid ðæm æscum 'with the/those ships' and mid æscum 'with ships'. The perfectivity of drehton 'attacked' in (13)

17 Someone could argue that the elimination of definite determiners might be impossible in OldEng - and there are no OldEng speakers to verify or reject the idea. But this is what linguistics is about, making hypotheses. 
is signaled through the temporal boundedness of pa hergas 'the raiding armies' and [mid] Jæm æscum '[with] the/those ships'. The imperfectivity of drehton in (14) is signaled through the non-bounded iterativity of hergas and [mid] æscum. The temporal (non)-boundedness of NP referents is mapped onto the referent of the verb, making it signal perfectivity or imperfectivity. Of course, for perfectivity to obtain, the verb must have a telic potential (Verkuyl 1972; 1993), which drehton 'attacked' here does have.

Being concerned with data related to articles/demonstratives, not so much zero article use, Sommerer's book contains few examples matching Verkuyl's imperfective schema. Here are two:

(15) a. Hy arerdon unrihte tollas

"They levied unjust tolls"

b. [...] and him aðas sworon

"[...] and swore him oaths"

(Sommerer 2018: 181, 209).

These are cases of imperfectivity in the form of non-bounded iterativity due to a lack of article/determiner, the two sentences thus falling into Verkuyl's imperfective schema. Although few, such examples reconfirm the thesis that some of Sommerer's (2018) data demonstrate the article-aspect interplay, without the author's knowledge. Gelderen's example (12a) and Sommerer's (13) show the involvement of the subject in aspectual composition through the definite article, beyond the authors' awareness; (15a-b) show the involvement of the direct object through the zero article.

The intriguing picture of aspect in MidEng/OldEng explicated compositionally through the impact of nominals becomes complete when example (2) is added - with the analysis above on the possibilities for unbounding each component. Subjects, direct and indirect objects participate in aspectual composition in MidEng/OldEng too, just like in ModEng.

The analysis of data showing that CA is observable in MidEng/OldEng will end with an element bearing some resemblance to a determiner/ article. It is the adverbial $p a$ 'then', called an "action marker" (Enkvist 1972; Wårvik 2011, Schulz 2014) and known for its high prevalence. ${ }^{18}$ It can be exemplified by this sentence from Wårvik (2011):

18 Namely, the third most frequent word in OldEng (Wårvik 2011). But one of the reasons for this extremely high prevalence is that $p a$ exercised various functions: conjunction, adverb, pronoun, demonstrative determiner (Wårvik 2011). 
Krasimir Kabakčiev: The Diachronic Mapping of Temporal Features between English...

(16) Pa (i) hie pa (ii) hamweard wendon mid pære herehype, pa (iii) metton hie micelne sciphere wicenga, and pa (iv) wip pa (v) gefuhton py ilcan dæge, and pa (vi) Deniscan ahton sige

'When (i) they then (ii) returned homeward with that booty, then (iii) they met a large fleet of pirates, and then (iv) fought against them (v) the same day, and the (vi) Danes had the victory'

It may be difficult to explain the alteration of $p a$ between an adverb and a determiner in (v-vi) above, but clearly all the verbs introduced by pa exhibit perfectivity: whether as an adverb or a determiner, $p a$ signals or amplifies it. Both Wårvik (2011) and Schulz (2014) are works exclusively devoted to pa. Wårvik does not discuss aspect, but Schulz (2014: 80) maintains that " $p a$-clauses are usually perfective". As the aspectual functions of $p a$ vis-à-vis aspect require further research, they will not be explored here. But they must obviously stand high in the list of priorities for analyses of the MidEng/OldEng aspectual system.

\section{The brain and its restricted storage capacity: a video- or a photo camera?}

Now it remains to show how exactly perfectivity is generated in real sentences/sequences such as (3a), (5a) in ModEng, and (2) in MidEng, i.e., not in hypothetical sentences, given that the main verb (made) has no own aspectual value and allows perfectivity and imperfectivity. Perfectivity arises syntactically through Verkuyl's perfectivity schema (without leaks), and cognitively through a mechanism enabling participants to be treated in the human mind as temporally bounded entities with precisely the same values. Native speakers of a language could admit that the child in (5a) can be seen as a bounded temporal stretch, starting where the woman starts to persuade the child to drink, and finishing where the child has already drunk (water from the well), but they might also argue that the well cannot possibly be seen as a bounded temporal stretch - because it is a stationary object.

This would be an incorrect line of reasoning. Sentences (3a), (5a), and all similar sentences are not about "individuals" (Carlson's 1977) such as "the woman" ("she"), "the child" and "the well" - complex concepts 
persisting through time, but encompass temporal stages of the relevant individuals. These are perceived by the observer-speaker and communicated to the hearer within the confines of the relevant sentences: (3a), (5a), etc. How they are perceived and communicated can be demonstrated by the following TV/video representation.

Suppose there exists a 45-minute video, from 00:00 to 45:00, about a woman, a child and a well as "individuals" in Carlson's (1977) terms, and that the time period in which the event in (5a) occurs is 30 seconds, between 30:30 and 31:00. This means that the woman, the child and the well, normally thought to be "physical objects" (Carlson's individuals), are actually nothing more than bounded temporal entities (stages of the relevant individuals), recorded as moving objects in the video (although they could be stationary just as well, i.e., standing still, not moving in space, yet moving in time) and lasting 30 seconds, between 30:30 and 31:00 (cf. Kabakčiev 2000: 99-100). In language, the temporal boundedness of entities/stages like these is directly marked by the article, as in ModEng, or signaled indirectly through the perfective aspect in the verb, as in Slavic (Kabakčiev 2000: 123-151). Note that in an imperfective (non-bounded iterative) sentence/sequence such as (3b), (8c), the referent of the bare noun in from wells will map its iterativity (indefinite recurrence) onto the referent of the verb, generating in it an imperfective (non-bounded iterative) reading, a recurring picture of a well/wells with an unknown beginning and an unknown end. ${ }^{19}$ Here the plurality of wells and the absence of an article, i.e., the absence of a marker of temporal boundedness, block the single-event reading and generate indefinite (non-bounded) iterativity, something expected to be a feature of the verb. The especially intriguing thing is that, instead of being denoted/signaled by the verb, the non-bounded iterativity stems from the NP wells. Note also the equally remarkable circumstance that the triggering of non-bounded iterativity cannot, in fact, be ascribed simply to the NP wells. Ultimately it is the zero article that is the source of imperfectivity (non-bounded iterativity)! ${ }^{20}$

Here above, and in Kabakčiev (2000), it was made clear that the article functions as a marker of temporal boundedness on nominals associated with

19 The indefinite recurrence will, in turn, be mapped onto the woman and the child (Kabakčiev 2000: 136ff; 2019).

20 Compare the insistence throughout an entire book that there is simply no such thing as a zero article; the zero article is "a myth" (Berezowski 2011). As for mapping temporal values in imperfective sentences, see the exact mechanism in Kabakčiev (2019). 
a verb (participants in situations), and that this temporal feature can easily be recognized when the relevant situation is presented videographically. Placing $a /$ the on nominals in sentences such as (3a), (5a), the brain both individual and collective, states: "each of these entities participating in this perfective situation is bounded in time"! ${ }^{21}$ Just like a standard PC today, the brain lacks the enormous memory capacity necessary to keep all situations as videos, with all the stages (bounded/non-bounded) of all individuals taking part in all situations permanently happening around. Hence, the brain resorts to this memory-saving technique, marking referents of nominals as bounded in time through the article - in English and similar languages, or marking the referent of the verb as bounded in time through the perfective aspect - in Slavic and similar languages. Obviously, the marking of temporal boundedness through an article is a photographic rather than a videographic technique. And just like the photo of a child eating a sandwich cannot reveal precisely whether the child ate the sandwich completely or not, whereas a video can, so do the articles (a\&the) signal boundedness, yet they do not carry this boundedness over to the speaker/hearer's awareness. The function of the articles (a\&the) to signal temporal boundedness of nominal referents remains hidden to the native speaker. But linguistic analyses here and elsewhere (Kabakčiev 2000; 2019) demonstrate that articles do signal temporal boundedness - within Verkuyl's perfective schema, in a covert, intricate and highly specialized manner.

\section{Possible paths for research into CA diachronically}

The analysis here, based on my version of the CA theory with its conception of the inverse dependence of markers of temporal boundedness in verbs and nouns and the mechanism of mapping temporal values between verbal and nominal referents (Kabakčiev 2000), complemented with Leiss' diachronic theory, reveals a causative link in the history of English between the loss of aspect and the emergence of articles. This link (assuming that it is true) ought to accompany the future description of the MidEng/OldEng aspectual

${ }^{21}$ Note that this is not "a general rule", it is valid for Verkuyl's perfective schema! For example, if the articles the and $a$ in The kid ate a fig mark boundedness, this boundedness is eliminated in The kid was eating a fig, due to the progressive (Kabakčiev 2000: 163179). 
system. Also, the view that every historical stage in a language displays an equilibrium between various aspectual devices, including peripheral ones, is here further corroborated with respect to article and aspect. But it must be complemented by future research into certain closely related spheres, especially case, and particularly the contrast between accusative and genitive-partitive, for which there are reasonable assumptions that it is intertwined with aspect.

Apart from the definite article (after its emergence), the ba determiner (adverb) and certain case markers, many other aspectual devices, less central, can be found in the different historical stages of English. One such device has been shown by Lavidas (2013): cognate constructions of the type smile a smile, laugh a laugh, etc. These were absent in OldEng and on the rise in MidEng. Similar constructions in ModEng, of the have a look type, are associated with perfectivity (Olsson 1961; Kabakčiev 2000: 211-215). It is precisely the mapping of boundedness from the nominal onto the verbal referent that clearly manifests the aspect connection of both groups of phrases. The absence of cognate constructions in OldEng is easily explained by the absence of an indefinite article in OldEng and its appearance in MidEng, but also with the diminishing presence of verbal perfectivity in OldEng and its final loss in MidEng. When grammatical devices in the verb (whether lexical or syntactic) for the denotation of perfectivity in a language diminish or disappear, as this happened in OldEng (loss of perfective verbs), it is logical for their absence to be compensated, and this can be effectuated in the domain of nominals. If/when the history of cognate constructions such as smile a smile, laugh a laugh etc. is fully revealed, this must also contribute to clarifying the history and role of the have a look type phrases - that play an even more significant part in the aspectual system of English. ${ }^{22}$

Another area of the OldEng aspectual system in need of a more precise description is the verbal lexicon with the changes occurring in it. Gelderen (2014: 104) describes the "re-analysis of verb meaning from object experiencer to subject experiencer" in the verb fear from the meaning 'to frighten' to the meaning 'to fear'. This is a change from telic to non-telic lexical meaning, hence from perfectivity to imperfectivity in a

22 The mapping of boundedness from a nominal onto a verb in English (John had a swim in the river), as explained in Kabakčiev (2000: 212), is included in the World Lexicon of Grammaticalization (Kuteva et al. 2019: 343) as a device related to grammatical perfectivization. 
Krasimir Kabakčiev: The Diachronic Mapping of Temporal Features between English...

sentence/clause. Recall that meanings of verbs as lexical items are a factor for explicating aspect within Verkuyl's schemata. It can be supposed that a certain portion of the OldEng verb lexicon underwent similar changes, that have to do with the aspect-article interdependence in synchronic and diachronic terms. Future research will reveal further the parameters of these changes.

\section{Conclusion}

The development from Proto-Indo-European through OldEng-MidEng to ModEng corroborates the idea of the inverse dependence of markers of boundedness (Kabakčiev 2000: 153-161) along the following lines. ProtoIndo-European featured a perfective-imperfective distinction in verbs. In most modern Indo-European languages the distinction was lost, while in some it was preserved. Where aspect was lost, articles gradually appeared, and today most modern Germanic languages feature a regular pattern of a definite and an indefinite article. All these facts are in consistence with what can be called the unified Leiss-Kabakčiev synchronic-diachronic theory of the aspect-article interplay (Leiss 2000; Kabakčiev 2000). To sum up, from the point of view of the continuum between VA and CA languages, where Proto-Indo-European and the Slavic languages occupy one end (VA), and most modern Germanic languages (English, German, Dutch, etc.) occupy the opposite end (CA), MidEng and OldEng can be defined as hybrid languages with their remnants of VA and simultaneously a CA system featuring no definite article in one stage and a gradual emergence of a definite article (and later an indefinite one) in following stages. It can easily be predicted that future research will reveal other features of the complex and highly intriguing system of aspect in the earlier stages of MidEng/OldEng, completely different from ModEng. But if grammarians and diachronic linguists continue to turn a blind eye to the regularities related to the articles - outlined here and initially discovered decades ago (Verkuyl 1972; Leiss 2000; Kabakčiev 1984; 2000), more years and decades may have to pass until it is finally recognized that the emergence of the definite article in MidEng/OldEng was a turning point in the history of English that occurred to fulfill the task of marking temporal boundedness on nominals, and thence perfectivity at the sentence/clause level. The definite and the indefinite article serve the explication of perfectivity 
in compositional terms in English: this is their true raison d'être. As for definiteness and indefiniteness, these are features of the articles that are also important, but less important and residual.

Acknowledgements. I would like to thank BELLS editors for their kind assistance and the reviewers for their notes and suggestions. I dedicate this paper to my mother Violeta Moskova, who passed away recently. She was an associate professor of Modern Russian, and I am most indebted to her for my never-ending curiosity and enthusiasm in linguistics.

\section{References}

Abraham, W. (1997). The Interdependence of Case, Aspect and Referentiality in the History of German: the Case of the Verbal Genitive. In: van Kemenade, A. and N. Vincent (eds.), Parameters of Morphosyntactic Change. Cambridge: Cambridge University Press, 29-61.

Abraham, W. (2017). Definiteness Effects across Categories in German. In: Sonja Z., M. Werner, B. Meisnitzer (eds.) Im Spiegel der Grammatik. Beiträge zur Theorie sprachlicher Kategorisierung. Tübingen: Stauffenburg Verlag, 277-303.

Abraham, W. and E. Leiss (2012). The Case Differential: Syntagmatic versus Paradigmatic Case - Its Status in Synchrony and Diachrony. Transactions of the Philological Society, Vol. 110(3). 316-341.

Bauer, B. (2007). The Definite Article in Indo-European: Emergence of a New Grammatical Category? In: Elisabeth Stark, Elisabeth Leiss and Werner Abraham (eds.). Nominal Determination. Typology, Context Constraints and Historical Emergence. Amsterdam. John Benjamins, 103-140.

Berezowski, L. (2011). The Myth of the Zero Article. London: Bloomsbury Publishing.

Bulatović, V. (2013). Modern Theories of Aspect and Serbian EL2 Learners. Belgrade English Language and Literature Studies, Vol. V., 65-79.

Bulatović V. (2019). Aspect Semantics and ESL Article Use. International Review of Applied Linguistics in Language Teaching. DOI: 10.1515/iral2019-0016

Bulatović V. (2020). Thinking for Speaking in the Right Aspect - on Whether Modern English Grammars Can Do More. Spanish Journal of Applied Linguistics. 33(2): 384-415. 
Carlson, G. N. (1977). Reference to Kinds in English. University of Massachusetts.

Carter, R. and M. McCarthy (2006). Cambridge Grammar of English, a Comprehensive Guide, Spoken and Written English Grammar and Usage. Cambridge: Cambridge University Press.

Czardybon, A. and J. Fleischhauer (2014). Definiteness and Perfectivity in Telic Incremental Theme Predications. In: Gerland, D., C. Horn, A. Latrouite and A. Ortmann (eds.). Meaning and Grammar of Nouns and Verbs. Düsseldorf: Düsseldorf University Press, 373-400.

Declerck, R., S. Reed and B. Cappelle (2006). The Grammar of the English Verb Phrase, Volume 1: The Grammar of the English Tense System, a Comprehensive Analysis. Berlin/New York: Mouton de Gruyter.

Downing, A. and P. Locke (2006). English Grammar. A University Course. London and New York: Routledge.

Drobnak, F. (1994). The Old English Preverbal ge- in the Light of the Theory of Language Change as Strengthening or Weakening. Studia Anglica Posnaniensia XXVIII, 123-141.

Eastwood, J. (2006). Oxford Practice Grammar. Oxford: Oxford University Press. Enkvist, N. (1972). 'Old English Adverb pa - an Action Marker?' Neuphilologische Mitteilungen 73, 90-96.

Fenn, P. (2010). A Student's Advanced Grammar of English. Tübingen: Narr Francke Attempto Verlag.

Fischer, S. (2005). Interplay between Reference and Aspect. In: Heusinger, K. von, G. A. Kaiser and E. Stark (eds.). Proceedings of the Workshop "Specificity and the Evolution/Emergence of Nominal Determination Systems in Romance". Konstanz, 1-16.

Fleischhauer, J. and A. Czardybon. (2016). The Role of Verbal Prefixes and Particles in Aspectual Composition. Studies in Language 40(1), 176-203.

Gelderen, E. van (2007). The Definiteness Cycle in Germanic. Journal of Germanic Linguistics 19(4), 275-308.

Gelderen, E. van. (2014). Changes in Psych-Verbs: a Reanalysis of Little v. Catalan Journal of Linguistics, Vol. 13, 99-122.

Gelderen, E. van (2018). The Diachrony of Verb Meaning: Aspect and Argument Structure. New York/London: Routledge.

Hawkins, J. (1978). Definiteness and Indefiniteness. Croom Helm. London. Heine, B. and T. Kuteva (2006). The Rise of Articles. The Changing Languages of Europe. Oxford: Oxford University Press, 97-139. 
Hewson, J. (1972). Article and Noun in English. The Hague/Paris: Mouton. Hogg, R. (2002). An Introduction to Old English. Edinburgh University Press. Edinburgh.

Huddleston, R. and G. K. Pullum (2002). The Cambridge Grammar of the English Language. Cambridge: Cambridge University Press.

Kabakčiev, K. (1984). The Article and the Aorist/Imperfect Distinction in Bulgarian: an Analysis Based on Cross-Language 'Aspect' Parallelisms. Linguistics 22, 643-672.

Kabakčiev, K. (2000). Aspect in English: a "Common-Sense" View of the Interplay between Verbal and Nominal Referents. Dordrecht: Kluwer.

Kabakčiev, K. (2017). An English Grammar: Main Stumbling Blocks for Bulgarians Learning English. Stuttgart: Mariana Kabakchiev Verlag.

Kabakčiev, K. (2018). Response: Fleischhauer and Czardybon Evade the Burden of Proof. Studies in Language 42(4), 967-969.

Kabakčiev, K. (2019). On the History of Compositional Aspect: Vicissitudes, Issues, Prospects. Athens Journal of Philology 6 (3), 201-224.

Kuteva et al. (2019). Kuteva, T., B. Heine, B. Hong, H. Long, S. Rhee, H. Narrog. World Lexicon of Grammaticalization. Cambridge: Cambridge University Press.

Langacker, R. (2008). Cognitive Grammar: a Basic Introduction. Oxford: Oxford University Press.

Lavidas, N. (2013). Null and Cognate Objects and Changes in (In) transitivity. Evidence from the History of English. Acta Linguistica Hungarica Vol. 60(1), 69-106.

Leiss, E. (2000). Artikel und Aspekt. Die grammatischen Muster von Definitheit. Berlin: de Gruyter.

Lindemann, J. W. R. (1970). Old English Preverbal ge-: Its Meaning. Charlottesville. The University Press of Virginia.

Lyons, C. (1999). Definiteness. Cambridge: Cambridge University Press.

Macleod, M. (2012). The Perfect in Old English and Old Saxon: the Synchronic and Diachronic Correspondence of Form and Meaning. St. John's College dissertation.

Młynarczyk, A. (2004). Aspectual Pairing in Polish. Utrecht: LOT.

Mustanoja, T. (1960). A Middle English Syntax. Helsinki.

Olsson, Y. (1961). On the Syntax of the English Verb. With Special Reference to Have a Look and Similar Complex Structures. Göteborg: Elanders Boktryckeri Aktiebolag. 
Quirk, R. et al. (1985), Quirk, R., S. Greenbaum, G. Leech and J. Svartvik. A Comprehensive Grammar of the English Language. London: Longman. Ringe, D. and A. Taylor. (2014). A Linguistic History of English. Volume II. The Development of Old English. Oxford: Oxford University Press.

Schulz, N. (2014). Syntactic and Pragmatic Functions of pa in Old English Prose and Verse. Bonn dissertation.

Schüller, S. (2005). Problematik der Darstellung von Aspektunterschieden in englischen Referenzgrammatiken. In: Herbst, T. (ed.). Linguistische Dimensionen des Fremdsprachenunterrichts. Würzburg: Königshausen and Neumann, 29-42.

Senn, A. (1949). Verbal Aspects in Germanic, Slavic, and Baltic. Language $25,402-409$.

Sommerer, L. (2018). Article Emergence in Old English: a Constructionalist Perspective. Berlin/Boston: de Gruyter.

Streitberg, W. (1891). Perfective und imperfective Aktionsart im Germanischen. In: Beiträge zur Geschichte der deutschen Sprache und Literatur (PBB) 15, 70-177.

Vendler, Z. (1957). Verbs and Times. The Philosophical Review 66, 143-160.

Verkuyl, H. (1972). On the Compositional Nature of the Aspects. Dordrecht: Reidel.

Verkuyl, H. (1993). A theory of Aspectuality. The Interaction Between Temporal and Atemporal Structure. Cambridge: Cambridge University Press.

Wårvik, B. (2011). Connective or 'Disconnective' Discourse Marker? Old English $p a$, Multifunctionality and Narrative Structuring". In: MeurmanSolin, A. and U. Lenker (eds). Connectives in Synchrony and Diachrony in European Languages (Studies in Variation, Contacts and Change in English, 8). Helsinki: VARIENG open access e-series (08 August 2021) <http://www.helsinki.fi/varieng/journal/volumes/08/warvik/>.

Wood, J. (2002). Tense and Aspect in Gothic: a Statistical Comparison of the Greek and Gothic Versions of St Mark's Gospel. Memorial University of Newfoundland.

Wood, J. L. (2007). Demonstratives and Possessives: from Old English to Present-Day English. In: Stark E., E. Leiss and W. Abraham (eds.), Nominal Determination. Typology, Context Constraints and Historical Emergence. Amsterdam. John Benjamins, 339-361.

Received: 19 December 2019

Accepted for publication: 15 August 2021 